\title{
Conducting Library Research
}

\begin{abstract}
Previous research studies are an excellent source of ideas for those planning to do research on library operations. Studies drawn from four areas-the structure of information, user behavior, policy decisions, and performance measures - are briefly discussed to illustrate how they may stimulate further research. The main theme of the paper is the importance to librarianship of having research carried out which replicates, challenges, or otherwise builds on previous research.
\end{abstract}

A

NYONE WHO IS ABOUT TO undertake a research study makes some assumptions-the fewer assumptions, the better; but it is impossible to begin any project without making at least one assumption. The following comments about conducting library research are based on the assumption that there is some sort of underlying order in the way libraries operate, that there are some phenomena that cause or result from other phenomena and that, if we look carefully enough, we can detect that order and those relationships.

In the words of one of the standard texts on scientific investigation: "The function of a science .... is to establish general laws covering the behavior of the empirical events or objects with which the science in question is concerned." 1 This is a short and simple statement, but one that has many implications if we try to apply it to libraries.

One of the implications of viewing librarianship as a field susceptible to scientific research is that we accept the possibility of eventually tying together the findings of all research into a broad explanation of the field.

As a result, we expect that all who report

Rose Mary Magrill is professor, School of Library Science, University of Michigan, Ann Arbor. This article is based on an address given at a conference in March 1979 at the University of North Carolina at Chapel Hill. research will recognize and note the limits of their own studies, explain in detail how they went about collecting and analyzing data, and give us the information we need to repeat their studies in other settings or to build on their studies by attacking the questions they raised and were not able to answer.

This view-that library science is a field where studies should have some relationship to each other (with the object of eventually establishing general laws for the field)-means that one of the best places to find an idea for research is in studies that have already been completed.

Any comments about possible research topics in librarianship can only touch the surface of a few of the areas which wait to be explored. However, one must begin somewhere, and I propose to begin by noting some of the recent studies that have received wide attention or that seem to me to be interesting because of the research questions they raise.

I have arbitrarily divided the studies into four groups, which I am calling (1) the structure of information-that is, studies about the ownership of information, the characteristics of various physical formats in which information is recorded, and the characteristics of producers of information; (2) user behavior-including studies about the people for whom we collect and process information; (3) policy decisions-studies about the organizations, policies, and proce- 
dures we set up to gather the information and serve the people; and (4) performance measures-studies on standards and measurements by which we judge our success.

\section{THE STRUCTURE OF INFORMATION}

It seems logical to start this discussion with a consideration of the raw materials from which libraries or information centers are built. There are many unanswered questions about the structure of information. Who actually owns information? Who should pay when information is transferred? To whom should the payment be made?

The report on library photocopying prepared by King Research for the National Commission on Libraries and Information Science is an example of a study that arose out of the need for more information on the possible effects of the new copyright law. ${ }^{2}$ In 1976 NCLIS awarded a contract to King Research "to provide estimates of the extent of photocopying and to study alternative royalty payment mechanisms." The National Science Foundation and the National Commission on New Technological Uses of Copyrighted Works (CONTU) also contributed to the funding. The study was based on data about photocopying activities collected from a national sample of about 300 libraries. These data were gathered in order to estimate the total volume of photocopying going on in libraries and also to estimate the amount of photocopied material that was actually under copyright protection.

Data for this study were collected during the year before the new copyright law went into effect. As the report itself warns, the behavior of everyone concerned may have changed after the copyright law went into effect in 1978. Do you know how (if at all) the photocopying practices in your own library changed after January 1, 1978? If there were changes, what effect did these have on the library's users? Do the changes appear to hinder any group's access to information? In academic institutions, what effect did the changes have on how instruction is carried on? On research?

With the five-year review of the copyright law scheduled for the early 1980 s, the need to evaluate in an objective manner the various guidelines and interpretations which accompanied the law should be obvious to us all. You do not have to do a major, funded study to make a contribution here. Careful, systematic, objective collection of data in your library, documenting what happens to the way people request and use various kinds of information, can help.

There is also much that we do not know about the various physical formats in which information is recorded. We could use more studies about the characteristics of various formats-which ones are most suitable for which types of information and which are best or preferred by which types of users.

For some types of materials (for example, periodicals), we have had a choice of physical formats for some time (microfilm, microfiche, or hard copy), and a fair amount of research has been done on whether hard copy is better or worse for various purposes than is a microform.

In comparison, we know relatively little about periodical indexes available in machine-readable form. For what purposes would our users prefer the machine-readable version to the hard-copy version? Under what circumstances can we afford to supply the preferred version? A number of studies have been reported on how specialists (particularly in science and technology) react to indexes in machine-readable form, but there is still much we do not know about how nonspecialists or the specialists in other fields might use them.

Let us move to another aspect of the structure of information. Much emotional debate has been provoked by the question of who pays the costs of information transfer. Public librarians, as well as academic librarians, have been active in this debate.

In 1978, the Public Library Association (PLA) published the results of a questionnaire survey of 930 public libraries, undertaken to gather some information on the state of fee charging in public libraries. ${ }^{3}$ The findings of this survey give some general indication of how widespread the practice of fee charging is, but the study raises more questions than it answers, partly because of definitional problems.

In this case, as the PLA report points out, the problems relating to definitions are hard to solve but must be attacked before much progress can be made in this area. 
What kind of payment is a fee, as opposed to a fine or a deposit or simply a payment for goods received? Should postal charges be considered fees? In this area, as in many others, we will not get very far in our attempts to study the problem until we decide exactly what we are looking for.

One major research study of 1976 , by Bernard M. Fry and Herbert S. White, looked at the producers of a major library resource-scholarly journals-as well as at the relationship between the publishers and libraries. Fry and White concluded that the economic problems caused for libraries by scholarly journals are not due to "wild and uncontrolled increases in the publication of such journals" nor to excessive profits on the part of the publisher. ${ }^{4}$

In addition, they found some indications that libraries were guided more by perceived value of a journal than by price when making a cancellation decision. However, the question of how librarians make decisions about starting or cancelling subscriptions was one that they identified for further research. We have had some reports on how individual libraries went about making decisions, but we need more systematic and controlled observation of this.

Even though Fry and White suspected that quality influences librarians' decisions about journal subscriptions, they concluded that, if a laissez-faire system is applied to journal publication, the results will not be what some librarians expect. They argued that university presses and other nonprofit publishers will be damaged the most and even predicted that "entire subject disciplines, such as the humanities, would not retain their viability in such a laissez-faire environment."5

Some libraries have made major budget shifts, reallocating funds from book purchases to journals in order to meet rising journal prices. We need to know more about the effects of these shifts, particularly on journals in the humanities. And, of course, we need to look at our relationships with producers of materials other than journals.

\section{USER BEHAVIOR}

The second group of research topics deals with the behavior of users. For all those interested in use of the library by nonspecial- ists, a good place to find out what we know (and also what we need to know) is in an article by Douglas Zweizig and Brenda Dervin, published in 1977 in Advances in Librarianship. ${ }^{6}$ The article, based on a USOE-funded study, "Strategies for Dealing with the Information Needs of Urban Residents," was intended as a critical review of the available literature on public library users. The authors identified and discussed sixteen studies published between 1949 and 1975 that attempted to measure characteristics of library users or nonusers and to give a picture of the "average user."

After reviewing the strengths and weaknesses of previous research, Zweizig and Dervin concluded that "the old model of user studies - the identification of who uses the library and how much-has been pushed as far as is helpful." They suggest moving on to the questions of why people use libraries and what do people find useful that libraries might be able to provide. "The important question then [for them] is not library use, not library users, but library uses. It is these 'uses,' these 'utilities' around which libraries can plan programs and can measure effectiveness." 7

In another discussion of the research needed in public libraries, Zweizig pointed out that public librarians still do not have the information they need on certain important questions: "Where does the greatest proportion of our population get the information it needs to function? What could the library do to benefit a larger proportion of the population? If the library instituted a new service, would it be accepted? Why does such a large proportion of the population not use the public library?"s Those questions, of course, are basic enough to keep public library researchers busy for some time, but they are also provocative when translated into academic settings.

Academic librarians have also been looking at how their libraries are being used. A recent major research effort on this subject is the NSF-funded study that was started at the University of Pittsburgh in 1975 and completed in 1978 - a study that had as its overall objective "to develop measures for determining the extent to which library materials are used, and the full cost of such use. ${ }^{9}$ 
There was a short summary of this study in the November 15, 1977, issue of Library Journal; but if you have read only that version, you have missed a great deal. The final report (272 pages) is a detailed discussion of methodology and findings of a study that analyzed more than 90 percent of all the external borrowing done at the Hillman Library (the central research library emphasizing the humanities and social sciences) of the University of Pittsburgh from late 1968 through the end of 1975 . In addition, sample studies were made of in-library use of monographs and of journals in six of the science/technology departmental libraries.

Perhaps the finding that created the most interest among other university librarians was the fact that 40 percent of the monographs acquired by the Hillman Library in 1969 had not circulated at all by 1975 . Of the 22,000-plus items that did circulate, slightly over 16,000 were borrowed during the year of initial acquisition or the year following. Data collected in this study tended to show that the chance of a book being circulated decreases rather rapidly as time passes after acquisition.

I have heard more than one librarian say that the rate of use of new materials in their libraries is higher than the Pittsburgh figure, and there have been critical comments published on the methodology, findings, and interpretations proposed by the Pitt study. ${ }^{10}$

This is certainly a place where more research could be done. The methodology used in the Pittsburgh study is described in the final report, and anyone ought to be able to replicate part of this study, at least on a small scale. In fact, one of the points tested in the Pitt study was how small a sample could be and still give reliable results in a library use study of this type. The Pittsburgh researchers concluded that random samples of loan records representing as little as three days' circulation produced correlations as high as .95 with the total population, when proportion of circulation by LC class was being studied.

What this means is that librarians who do not have complete retrospective circulation data available in machine-readable form, or who do not have the time or money to undertake a large study, can use much smaller samples to identify broad usage patterns within LC classes.

The Pittsburgh study presents a massive amount of data collection and analysis. The report is generally clear and easy to read for a research study of this type and offers a number of hints about how books and journals circulate in one large research library. I doubt, however, if anyone could read that study without coming up with a new research question every few pages. One study cannot answer all parts of any library problem, but a clearly reported piece of research can offer all sorts of leads to other research topics.

\section{POLICY DECISIONS}

The third area of research outlined earlier-the area referred to as policy decisions-can include any research that looks at the way we set up and operate libraries. Here I choose to overlook many important areas of library operation and mention three that particularly interest me-availability rates, resource sharing, and forms of library catalogs.

For a long period of time we concentrated on building bigger and better collections and bigger and better catalogs to enable people to find what was in those collections, while establishing circulation policies that had little relationship to anything except our own record-keeping convenience. We reached the point when some people pointed out that the best way to judge the effectiveness of decisions about acquisition, cataloging, circulation, and also binding and weeding is to look at how satisfied or frustrated users are when they come to the library looking for specific materials. Buckland's 1974 publication, Book Availability and the Library User, drew together many of the threads of this area of research. ${ }^{11}$

Other examples of user satisfaction studies (or user frustration studies, depending on your point of view) are the studies done at Case Western Reserve University (CWRU) and reported by Saracevic and others in College \& Research Libraries and by Kantor in the Journal of the American Society for Information Science. ${ }^{12}$

The CWRU researchers looked at why specific author/title searches were not successful. They used a branching technique to 
try to determine the overall effect on availability of such factors as number of items that could not be found on the shelves because they were in circulation; number that could not be found because they were missing, misshelved, not yet reshelved, repaired, etc. (referred to as "library malfunctions"); and the number that could not be found because of user error, such as missing the item in the catalog, copying the wrong call number, looking in the wrong collection, etc.

The techniques used in the CWRU research could certainly be applied to other libraries and might tell you a great deal about how well your library is satisfying some users (that is, those with specific requests) and what you ought to do about it. If user error is accounting for a lowered availability rate, then some sort of user education may be in order. If "library malfunctions" are causing frustration, then maybe you need more shelvers, better shelvers, or something else. All of these points are worth investigating.

Discussion of resource sharing pervades librarianship today. Everyone agrees that decisions about resource sharing can potentially influence all aspects of library operation, but few people would presume to explain how all of this will happen. Two of the studies mentioned earlier address resource sharing.

The Fry and White study on the publishing of scholarly journals concluded that interlibrary cooperation in acquisition, lending, and copying journals would affect specific publishers but that more data would be needed to determine whether scholarly journal publishers as a whole would be hurt. They also urged investigation of the motives of librarians in joining consortia and networks.

The Pittsburgh study gave much attention to the possible implications of resource sharing, but still concluded with a list of twelve unanswered questions-any one of which could stimulate numerous studies.

"Closing the catalog" seems to be the watchword for many librarians right now. There has been so much discussion on the topic of closing, freezing, or in some way altering the physical forms of catalogs in the last few years that I hesitate to cite any particular study which might stimulate your thinking or which would summarize for you what we already know.

Individual libraries that have made significant changes in their catalogs (University of Toronto, Ohio State University, New York Public Library, New York State Library, National Library of Medicine, etc.) have been described both formally and informally. Many libraries have prepared position papers on what their own options for their local catalogs will be when the Library of Congress makes it changes to adopt AACR 2.

There are all kinds of possible research questions being tossed around-questions about conversion costs, maintenance costs, costs that would occur if the catalog is not closed, costs that would occur if it is closed. ${ }^{13}$ There are also questions about the purposes now served by a library catalog and what library staff and library users really need in the way of a catalog.

\section{Performance Measures}

The last area of research is the one tentatively called "performance measures." What is referred to, though, is not only research concerned with identifying the statistics that give the most information about how a library is performing, but also research that attempts to standardize definitions and measurement techniques so that the results of one study can actually be compared with the results of another.

In an interview reported in the December 1978 issue of the ASIS Bulletin, Howard Resnikoff, the new director of the Division of Information Science and Technology at the National Science Foundation, was quoted as saying on this subject: “... standards make possible uniform comparison of the results of different experiences. Standard data bases would make it possible for people to conduct experiments on a common data base that everyone agrees has certain properties so that results can be measured and compared. No field is a science until it has standards and measures." 14

Public librarians have been particularly active in looking for standard definitions and measures. Early in this decade, the PLA 
sponsored a study on the measurement of effectiveness in public libraries-a study that resulted in such publications as the one by DeProspo and others called Performance Measures for Public Libraries and the datagathering manual by Altman and others. ${ }^{15}$ Although the PLA measurement project was never completed, it has received a great deal of attention. The approach and methodology developed by DeProspo and Altman have been used in a number of subsequent studies in several types of libraries.

A more recent effort by LAMA's Committee on Statistics for Public Libraries, titled The Collection and Use of Public Library Statistics by State Library Agencies: A Compilation of Forms and edited by Kenneth Shearer, attempts to determine what statistics the various states require of their public libraries (and also why they are required-legislative mandate, etc.) and makes some suggestions on how state collection of statistics could be improved. ${ }^{16}$

Academic librarians have been goaded into looking more closely at the meaning and usefulness of their own statistics by several outside forces-state legislators, university administrators, members of university program evaluation committees, and specialists in other fields such as Fritz Machlup, who said, in effect, that university librarians were not collecting enough statistics or the right kind of statistics to be able to show what they were doing. ${ }^{17}$

Some of the studies I mentioned earlierLynch's report on public library fees and Fry and White's study of journal publishing - complained about the difficulty of doing survey research when there are no commonly accepted definitions of terms or when statistics are not kept and reported in a uniform way. If you are interested in delving into past research on measurement, look at Lancaster's 1977 publication on measurement and evaluation. ${ }^{18}$ It brings together studies from all areas of library service and ought to stimulate your thinking along these lines.

The point made at the beginning of this paper-that scientific research builds on itself until a clear pattern emerges of the important relationships in a field-should be reemphasized here. Without measures that have a consistent meaning from one study to another, we cannot hope to have coordinated and useful research in librarianship.

\section{Conclusions}

I want to end with a couple of additional-and I hope practical-suggestions for approaching research. From a practicing librarian's point of view, the most effective way to look for research topics may be for a group of librarians to identify cooperatively the problems that need to be studied within a region, a state, or at least within an individual library, establish priorities for these research needs, and look at how small, manageable, affordable projects might fit into the picture.

One of the first steps in this approach would be to bring together the bits and pieces of what has already been done and to disseminate this information to all those who might want to become involved in research. Then, as new studies are undertaken, their progress can be monitored and their results fed back into the summary of what we know, thereby redefining what we need to know.

Another suggestion I want to make is that anytime you find yourself making an assumption about what your library users might want or how they might react to a change in one of your library procedures or programs, stop and think about that assumption; you may have identified a viable research topic.

Douglas Waples, in one of the first guides on how to do research in libraries, said: "To check the worth of assumptions before they are acted upon is the essential purpose of research." He pointed out that research is simply a matter of recognizing and stating doubtful assumptions, gathering evidence to test them, and adding the revised (or supported, as the case may be) assumption to the body of knowledge about librarianship. As Waples said: "Shorn of its academic jargon and complicated machinery, research is merely a name for the look before the leap, which is plain common sense." 19

\section{REFERENCES}

1. Richard B. Braithwaite, Scientific Explanation (Cambridge, England: University Pr., 1953), p.1. 
2. King Research, Inc., Library Photocopying in the United States: With Implications for the Development of a Copyright Royalty Payment Mechanism (Washington, D.C.: National Commission on Libraries and Information Science, 1977).

3. Mary Jo Lynch, "Confusion Twice Compounded: Report of a PLA Survey on Fees Currently Charged in Public Libraries," Public Libraries 17:11-13 (Fall 1978).

4. Bernard M. Fry and Herbert S. White, Publishers and Libraries: A Study of Scholarly and Research Journals (Lexington, Mass.: Lexington Books, 1976), p. 123.

5. Ibid., p. 122.

6. Douglas Zweizig and Brenda Dervin, "Public Library Use, Users, Uses: Advances in Knowledge of the Characteristics and Needs of the Adult Clientele of American Public Libraries," Advances in Librarianship 7:23155 (1977).

7. Ibid., p.251-52.

8. Douglas L. Zweizig, "With Our Eye on the User: Needed Research of Information and Referral in the Public Library," Drexel Library Quarterly 12:48 (Jan.-April 1976).

9. Allen Kent and others, Use of Library Materials: The University of Pittsburgh Study (New York: Marcel Dekker, 1979).

10. "Pittsburgh University Studies of Collection Usage: A Symposium," Journal of Academic Librarianship 5:60-70 (May 1979); University of Pittsburgh, Senate Library Committee, "Report on the Study of Library Use at Pitt by Professor Allen Kent, et al." (Pittsburgh: The Committee, 1979). Available through ERIC: ED 178100.

11. Michael K. Buckland, Book Availability and the Library User (New York: Pergamon, 1975).

12. T. Saracevic and others, "Causes and Dynamics of User Frustration in an Academic Library," College \& Research Libraries 38:718 (Jan. 1977); Paul B. Kantor, "Availability Analysis," Journal of the American Society for Information Science 27:311-19 (Sept.Oct. 1976).

13. A column of "News about AACR 2 Implementation Studies" appears in the RTSD Newsletter.

14. "NSF's New Information Science Program," Bulletin of the American Society for Information Science 5:27-28 (Dec. 1978).

15. Ernest R. DeProspo and others, Performance Measures for Public Libraries (Chicago: American Library Assn., Public Library Assn., 1973); Ellen Altman and others, A Data Gathering and Instructional Manual for Performance Measures in Public Libraries (Chicago: Celadon Pr., 1976).

16. The Collection and Use of Public Library Statistics by State Library Agencies: A Compilation of Forms, edited with an analysis by Kenneth D. Shearer (Chicago: American Library Assn., Library Administration and Management Assn., 1978).

17. Fritz Machlup, "Our Libraries: Can We Measure Their Holdings and Acquisitions," AAUP Bulletin 62:303-7 (Oct. 1976).

18. F. W. Lancaster, The Measurement and Evaluation of Library Services (Washington, D.C.: Information Resources Pr., 1977).

19. Douglas Waples, Investigating Library Problems (Chicago: Univ. of Chicago Pr., 1939), p.vii. 